\title{
Incubation inside the bovine rumen
}

\author{
BY J. W. CZERKAWSKI \\ Hannah Dairy Research Institute, Ayr \\ (Received I3 March I967-Accepted 7 fune 1967)
}

\begin{abstract}
r. Details are given for the construction and use of an apparatus for the incubation of rumen liquor in semi-permeable sacs inside the bovine rumen. It was found practicable, using one animal, to incubate simultaneously samples of strained diluted rumen liquor in three identical vessels, each of 100-120 ml capacity, for periods of up to $23 \mathrm{~h}$.

2. The optimal conditions for experiments of this type were investigated. It was shown that, under the conditions used, the $\mathrm{pH}$ value of the reaction mixtures varied little compared with the $\mathrm{pH}$ changes that occurred inside the rumen, and that the sampling technique was satisfactory.

3. The effects of the size and type of inoculum were also investigated. The microbial growth, measured by increases in turbidity and in concentration of protein, was greatest when the rumen liquor inoculum constituted about $20 \%$ of the reaction mixture and when the protozoa and large food particles were removed.

4. The apparatus was used to study microbial growth and hydrogenation of fatty acids in rumen liquor.
\end{abstract}

There are two main lines of approach to the study of biochemical reactions in the rumen. Experiments in vitro involve collection of samples of rumen contents from the rumens of slaughtered animals or from live animals provided with rumen cannulas, and the subsequent incubation of these contents in the laboratory with suitable substrates under conditions which approximate to those in the intact rumen (Warner, 1956). This approach is suitable for theoretical studies (e.g. Dawson, Ward \& Scott, 1964) and in studies of a practical nature such as evaluation of the quality of forages (Alexander \& McGowan, I966), but there is always a danger that the results obtained in this way do not apply in the rumen in vivo. The other line of approach is to make studies in vivo, and work of this type is usually confined to the use of animals from which rumen contents can be obtained as required through a suitable cannula or by a stomach tube. The advantage of this method is that the reactions occur in the natural environment. However, the experiments in vivo are subject to many disadvantages. They are usually lengthy and laborious and, with large animals such as cattle, sampling on a large scale is necessary to obtain the required accuracy. Since the contents of a rumen are in a state of flux, it is very difficult to study the kinetics of the various biochemical reactions that occur in the rumen. The rumen contents are heterogenous and it is almost impossible to obtain a representative sample even of the more fluid part of the contents (rumen liquor). In fact the difficulty of reproducible sampling is so great that some workers have completely emptied the rumen, after which the contents were mixed, sampled and returned to the rumen (Hale, Duncan $\&$ Huffman, 1947).

The method to be described is a compromise between those two different approaches inasmuch as the rumen contents were incubated in semi-permeable sacs inside the 
bovine rumen. Some important components of the rumen contents (micro-organisms, proteins and certain substances associated with micro-organisms) are confined to a closed system and yet share the medium with the free-flowing organisms in the rest of the rumen. It should be possible, with this apparatus, to study the kinetics of many reactions occurring in the rumen under conditions approaching those existing in vivo. Some preliminary results with a prototype apparatus have been reported briefly (Czerkawski, r966); a more detailed description is given here.

\section{EXPERIMENTAL AND RESULTS}

\section{Animals and diets}

Two lactating Ayrshire cows fitted with rumen cannulas (Balch \& Cowie, 1962) were used. Their daily diet during the earlier part of these studies consisted of $8 \mathrm{~kg}$ poor-quality hay and $4 \mathrm{~kg}$ commercial cubes ( $16 \%$ crude protein) given in four equal meals at $06.00, \mathrm{Ir} .00, \mathrm{I} 6.00$ and $23.00 \mathrm{~h}$. Later this was changed to $6 \mathrm{~kg}$ hay and $6 \mathrm{~kg}$ cubes (rich diet).

\section{Apparatus}

Construction. Essentially, the apparatus consisted of three cylindrical vessels mounted side by side in an oval block of Perspex which fitted into a large rumen cannula so that the greater part of each vessel was immersed in the contents of the rumen. Each vessel contained dialysis tubing that was supported between two perforated cylinders. The vessels were provided with arrangements for stirring and sampling (Pl. I).

The outer supporting cylinders (length, I I in.; internal diameter, $\mathrm{I} \frac{1}{4}$ in.) were constructed of extruded high-density polythene netting (Netlon; Spicers Ltd, Loughton, Essex). The specifications given by the manufacturers for the Netlon used for the outer supporting cylinders were as follows: mesh count/in., 4; weight range, $3^{6} \mathrm{~g} /$ linear $\mathrm{ft}$. The inner supporting cylinders (length, 9 in., internal diameter, $\mathrm{I} \frac{1}{4} \mathrm{in}$.) were constructed of a more flexible and much finer grade of Netlon, for which the specifications given by the manufacturers were: mesh count per in., 6 ; weight range, $2 \mathrm{~g}$ /linear ft. The oval block in which the vessels were mounted was cut from a slab of Perspex ( $1 \frac{1}{2}$ in. thick) and was shaped to fit into a fistula similar to that described by Balch \& Cowie (1962). Three holes were bored in the mounting block and a coarse thread was machined into the upper third of each hole (Fig. I). The lower part of each hole was enlarged to accommodate the perforated cylinders, but a projecting ring of Perspex $(L)$ was retained midway between the upper and lower surfaces of the mounting block $(B)$. An outer perforated cylinder of Netlon $(O)$ was inserted up to the projecting ring in the enlarged lower part of each hole and was cemented to the Perspex block as follows. A soft polythene tube (outer diameter equal to the inner diameter of the outer perforated cylinder) was pushed inside the outer cylinder so that it made firm contact with the projecting ring. The outer perforated cylinder was then cemented $(A)$ in position by pouring into the spaces between the mounting block and soft polythene tube epoxy resin (Araldite MY 750; Ciba Ltd, Duxford, Cambridge). The soft polythene tube thus acted as a mould and prevented the resin from running into 
the thread above the projecting ring. After the resin had set, the soft polythene tube was easily removed by prising it away from the inner surface of the perforated cylinder. When the outer perforated cylinders had been cemented in position, the open ends were rounded by gently pressing the ends into a hot crucible. Perspex stoppers $(M)$ were made with matching threads to fit into the upper part of each hole

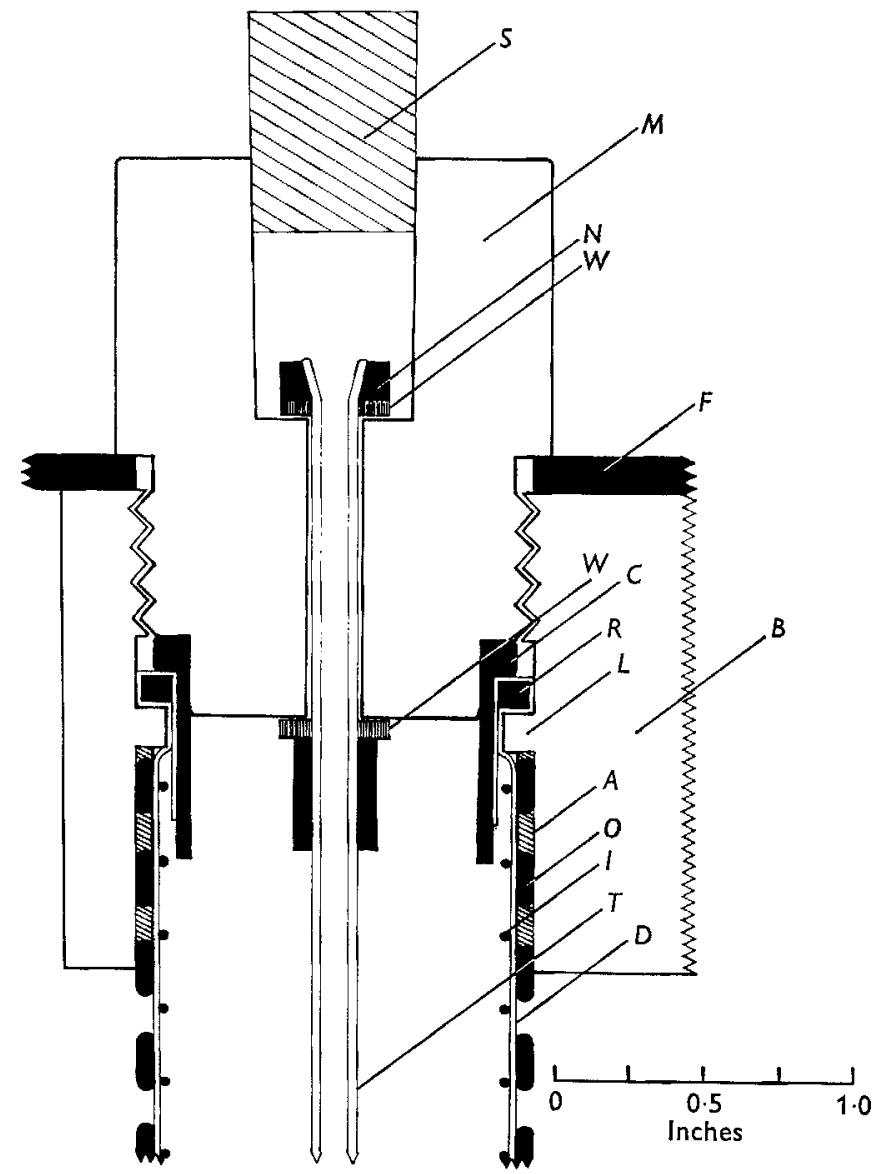

Fig. I. A scale diagram showing the construction and arrangement of the upper part of one of the reaction vessels. 'The rubber bung $(S)$ fits in the machined perspex stopper $(M)$. The top of the stirrer tube $(T)$ is splayed out and provided with a collar $(N)$ made of a short piece of rubber pressure tubing. Rubber $\operatorname{cover}(F)$ fits into the flap of the fistula. The stirrer tube is held in position by the tightly fitting rigid polythene washers $(W)$. Collar $(C)$ is made of soft polythene tubing (Portex), its lip resting on a ring $(R)$, made of the same material. The ring rests on the Perspex ledge $(L)$ which is an integral part of the block $(B)$. The dialysis tube $(D)$ is sandwiched between the ledge $(L)$ and the Perspex ring $(R)$; it passes over the ring and is held down by the lipped polythene collar $C$. The dialysis tube $D$ is sandwiched between the inncr perforated cylinder $(I)$ and the rigid outer perforated cylinder $(O)$. The latter is fixed rigidly in the block $B$ with the resin $(A)$.

in the mounting block. A hole was bored through the centre of each stopper and the upper part of each hole was enlarged so that rubber bungs (diameter, $\frac{9}{1} \overline{6}$ in.) could be inserted. The stirrer tubes $(T)$ were of high density polythene (Portex Plastics Ltd, 
Hythe, Kent; internal diameter, $3 \mathrm{~mm}$ ) and their external diameters were such that they could pass through the holes in the stoppers. At one end the sampling tubes were widened $(N)$ so that they could be held in position by collars $(W)$ situated on the shoulders of the holes bored through the stoppers. Spiral strips of polythene sheet were warmed, extended and then fixed on to the sampling tubes to form stirring worms as shown in P1. I. The stirrers were operated by rotating tubes that could grip the widened ends of the sampling tubes tightly. Samples were withdrawn from the apparatus with a small syringe.

Assembly and operation. Dialysis tubes (Visking, length, $\mathrm{I} 5$ in.; flat diameter, $\mathrm{I} \frac{1}{2}$ in.) were wetted and doubly knotted at one end. The inner supporting cylinders, also rounded at one end, were inserted into the dialysis tubes which were then filled with water to check for leaks. The water was removed and the dialysis tubes containing the inner supporting cylinders were pushed through the holes in the mounting block into the outer supporting cylinders. The dialysis tubes were filled with water again. Soft polythene washers were inserted into the dialysis tubes until they rested on the projected ring of Perspex (Fig. I). Thus, the dialysis tubing $(D)$ was sandwiched between the polythene washer $(R)$ and the Perspex ledge $(L)$. The excess dialysis tubing was cut off and the top part was folded in over the polythene washer. A soft polythene collar $(C)$ was then inserted so that the dialysis tube was held securely in position. At this stage it is advisable to leave the apparatus for a few hours to make sure that the dialysis tubes are undamaged and free from leaks.

The cover of the fistula was removed and about $400 \mathrm{ml}$ of rumen liquor were collected, by the device described by Alexander \& McGowan (ig66), and strained directly through several layers of muslin into a jar kept at $40^{\circ}$. The semi-solid contents inside the rumen were pushed aside and the empty apparatus was inserted so that the top of the mounting block coincided with the top of the fistula. The rubber cover $(F)$ was then fitted into the flap of the fistula, and the stoppers complete with stirrers were screwed in tightly.

Mixtures of artificial saliva (McDougall, 1948), rumen liquor and solutions of substances under investigation were introduced into each vessel by means of a large syringe $(100 \mathrm{ml})$. The reaction mixtures were stirred and the openings in the stoppers were closed with rubber bungs. The total capacity of each vessel was $r_{4} \circ \mathrm{ml}$, but it was found subsequently that the most reliable results were obtained when only $100-120 \mathrm{ml}$ of the various incubation mixtures were used and when the total volume of all the samples taken during an experiment did not exceed $50-60 \mathrm{ml}$.

\section{Methods of analysis}

Determination of protein nitrogen. Samples of rumen liquor or of the liquid being studied $(\mathrm{I}-4 \mathrm{ml})$ were pipetted into centrifuge tubes $(\mathrm{I} .5 \times 10 \mathrm{~cm})$, and the volumes were made up to $5 \mathrm{ml}$ with water. Equal volumes of solutions of trichloroacetic acid in water $(10 \%, \mathrm{w} / \mathrm{v})$ were added and the contents were mixed. The tubes were placed in a water bath at $95^{\circ}$ for $10 \mathrm{~min}$ and were then cooled and centrifuged at $700 \mathrm{~g}$ for I $5 \mathrm{~min}$. The clear supernatant fluid was decanted and rejected.

In some experiments the residues were washed with $5 \%$ trichloroacetic acid and 
hydrolysed with concentrated sulphuric acid in microKjeldahl flasks (Jacobs, I960). The nitrogen content of the hydrolysate was then determined by the ninhydrin method of Jacobs (1960).

In other experiments the protein contents of the trichloroacetic acid precipitates were determined as follows. The residues were each extracted with $5 \mathrm{ml} 0.5 \mathrm{~N}-\mathrm{NaOH}$, by adding the alkali, shaking, and heating in a water bath at $95^{\circ}$ for $5 \mathrm{~min}$. The samples were cooled and centrifuged at $700 \mathrm{~g}$ for $10 \mathrm{~min}$. The supernatant fluids were decanted and the residues extracted again in the same way. The extracts were collected together and made up to a suitable volume with $0.5 \mathrm{~N}-\mathrm{NaOH}$ solution. The degree of dilution varied with the diet of the animal, and $\mathrm{I} \cdot 0 \mathrm{ml}$ of strained rumen liquor usually required a final volume of $15^{-25} \mathrm{ml}$.

Duplicate samples of the extracts $(\mathrm{r} \cdot 0 \mathrm{ml})$ were pipetted into test tubes and the protein concentrations were then determined by the method of Lowry, Rosebrough, Farr \& Randall (1951) as modified by Tennies \& Feng (1965). Solutions of bovine serum albumin $(100-200 \mu \mathrm{g} / \mathrm{ml}$ of $0.5 \mathrm{~N}-\mathrm{NaOH})$ were used as standards and the reagent blank consisted of $0.5 \mathrm{~N}-\mathrm{NaOH}$.

In this method the alkaline copper reagent was prepared on the day of use by mixing $\mathrm{I} \cdot 0 \mathrm{ml}$ of a solution of potassium sodium tartrate tetrahydrate $(3.375 \%, \mathrm{w} / \mathrm{v})$ with $\mathrm{r} \cdot 0 \mathrm{ml}$ of a r. $25 \%(\mathrm{w} / \mathrm{v})$ solution of $\mathrm{CuSO}_{4} \cdot{ }_{5} \mathrm{H}_{2} \mathrm{O}$ and making the volume up to I $00 \mathrm{ml}$ with $2.5 \%(\mathrm{w} / \mathrm{v}) \mathrm{Na}_{2} \mathrm{CO}_{3}$ (anhydrous). The copper reagent $(4 \mathrm{ml})$ was added to each sample of protein solution and the tubes were shaken. After the tubes had remained at room temperature for $10 \mathrm{~min}, \mathrm{I} \cdot 0 \mathrm{ml}$ of $0.5 \mathrm{~N}$ Folin-Ciocalteau reagent was added to each and the contents were mixed and allowed to stand for $30 \mathrm{~min}$. The optical densities of the solutions were determined at $75^{\circ} \mathrm{m} \mu$.

Lipid analyses. The lipids were extracted by a modification of the method of Folch, Lees \& Stanley (1957). They were saponified, and the total fatty acids were isolated and esterified with methanol as described by Kates (1964). The amounts of acids were usually determined gravimetrically but, when the amounts were too small for that, the method of Duncombe ( 1963 ) was used. The methyl esters of the fatty acids were analysed by gas-liquid chromatography on columns of polyethylene glycol adipateChromosorb W $(\mathrm{r}: 9, \mathrm{w} / \mathrm{w})$ or Apiezon L-Chromosorb W $(\mathrm{r}: 9, \mathrm{w} / \mathrm{w})$ operated at $197^{\circ}$ in a Pye-Argon Gas Chromatograph.

Determination of total volatile fatty acids. Samples of the liquid being studied were mixed with equal volumes of $2.5 \%(\mathrm{v} / \mathrm{v}) \mathrm{H}_{2} \mathrm{SO}_{4}$ in saturated solution of $\mathrm{MgSO}_{4}$. They were centrifuged for $15 \mathrm{~min}$ at $700 \mathrm{~g}$ and portions of the supernatant fluid $(0.5 \mathrm{ml})$ were used for estimation of the volatile acids by the micro-diffusion method of Conway (1962).

Turbidometric measurement of microbial growth. In many exploratory experiments samples were diluted with artificial saliva and the microbial growth was determined by measuring the increase in optical density in a colorimeter (EEL; Evans Electroselenium Ltd) with a red filter. This procedure was particularly useful in experiments in which suspensions of rumen bacteria were used rather than samples of whole strained rumen liquor. 


\section{Preliminary studies with the apparatus}

The $p H$ values of reaction mixtures. The dialysis sacs were tested for leaks by filling the vessels with water and inserting the apparatus for up to $24 \mathrm{~h}$ in the rumen. The protein concentrations inside the sacs remained negligible. The changes in $\mathrm{pH}$ value were then investigated as follows.

The experiment started just after the $06.00 \mathrm{~h}$ feed. Vessel I contained I $20 \mathrm{ml}$ strained rumen liquor, and vessel 3 contained $60 \mathrm{ml}$ rumen liquor mixed with $60 \mathrm{ml}$ artificial saliva (McDougall, I948). Vessel 3 had no dialysis membrane and was used in this experiment for sampling rumen contents in the vicinity of the reaction vessels.

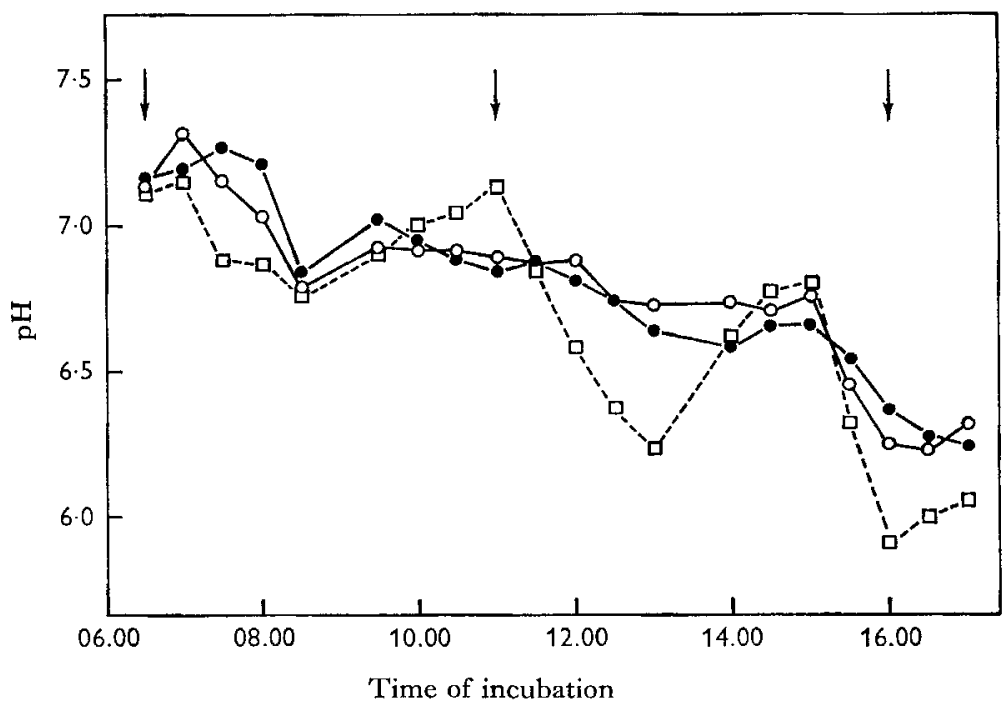

Fig. 2. Variations in the pH of the rumen contents and of the samples incubated in the dialysis sacs inside the rumen during the day. The arrows indicate the times at which the cow was fed. $\square-\square$, rumen liquor sampled directly from the rumen; - - , strained undiluted rumen liquor incubated inside the sac; $\mathrm{O}-\mathrm{O}$, strained rumen liquor, diluted with an equal volume of artificial saliva and incubated inside the sac.

Small samples were withdrawn throughout the day and the $\mathrm{pH}$ was measured immediately with a Pye $\mathrm{pH}$ meter. The results of a typical experiment are shown in Fig. 2. The $\mathrm{pH}$ of the rumen contents tended to change in a cyclic manner corresponding roughly to the feeding periods. In general it tended to fall after a meal and then rise before the next meal. The $\mathrm{pH}$ of both undiluted rumen liquor and rumen liquor diluted with artificial saliva in the reaction vessels varied to a smaller extent. It can be seen (Fig. 2) that after the initial period between 06.00 and $08.00 \mathrm{~h}$ there was a period of about $6 \mathrm{~h}$, during which the $\mathrm{pH}$ within the dialysis sacs tended to drop steadily from 6.9 to $6 \cdot 6$. This period was chosen for most of the subsequent incubations.

The volatile fatty acids contribute to the changes in the $\mathrm{pH}$ of the rumen contents and it was of interest, at this point, to investigate their behaviour during incubations. The results of a representative experiment are given in Table $\mathbf{1}$, which also gives the 
pertinent experimental details. The concentrations of the volatile acids in the samples withdrawn directly from the rumen (by by-passing the apparatus) were variable, showing an expected increase after the $\mathrm{I} 1.00 \mathrm{~h}$ feed. The concentration of the acids in the vessel that contained no rumen liquor increased steadily to a value which existed at that time in the rumen. When rumen liquor was present in the dialysis sacs, the increase in the concentration of the volatile acids was partly due to their formation inside the sacs, because the rate was greater when the level of added substrate was increased. At the end of incubation the concentrations of the acids in these two vessels were not very different from the concentration inside the rumen.

Table I. Concentrations ( $m$-equiv./100 $\mathrm{ml}$ ) of volatile fatty acids taken from the rumen of a cow and from the incubation vessels

\begin{tabular}{|c|c|c|c|c|}
\hline \multirow[b]{3}{*}{ Time } & \multicolumn{4}{|c|}{ (Values are means of two estimations) } \\
\hline & \multirow{2}{*}{$\begin{array}{c}\text { Samples taken } \\
\text { directly from } \\
\text { the rumen } \\
\text { during } \\
\text { incubation }\end{array}$} & \multicolumn{3}{|c|}{ Inside the dialysis sacs } \\
\hline & & Vessel I * & Vessel $2 \dagger$ & Vessel $3 \ddagger$ \\
\hline 09.00 & $12 \cdot 5$ & $x-6$ & $7 \cdot 2$ & $6 \cdot 9$ \\
\hline I I.OO & IO. I & $6 \cdot 3$ & $9 \cdot 0$ & $9 \cdot 2$ \\
\hline 13.00 & $13 \cdot 9$ & $9 \cdot 1$ & 10.4 & $12 \cdot 5$ \\
\hline 15.00 & $12 \cdot 2$ & I $1 \cdot 2$ & II:9 & $13 \cdot 7$ \\
\hline 17.00 & II.9 & $12 \cdot 3$ & $I_{3} \cdot 0$ & $12 \cdot 2$ \\
\hline
\end{tabular}

* $60 \mathrm{ml}$ artificial saliva and $60 \mathrm{ml}$ water.

$+60 \mathrm{ml}$ artificial saliva (containing $100 \mathrm{mg}$ glucose and $50 \mathrm{mg}$ urea) and $60 \mathrm{ml}$ strained rumen liquor.

\pm The same as vessel 2, except that the glucose concentration was increased to $200 \mathrm{mg} / \mathrm{r} 20 \mathrm{ml}$.

Table 2. Concentrations of ash and organic matter in samples taken from the rumen of a cow and from the incubation vessels ( $\mathrm{g} / \mathrm{100} \mathrm{ml}$ sample)

(Values are means for two estimations)

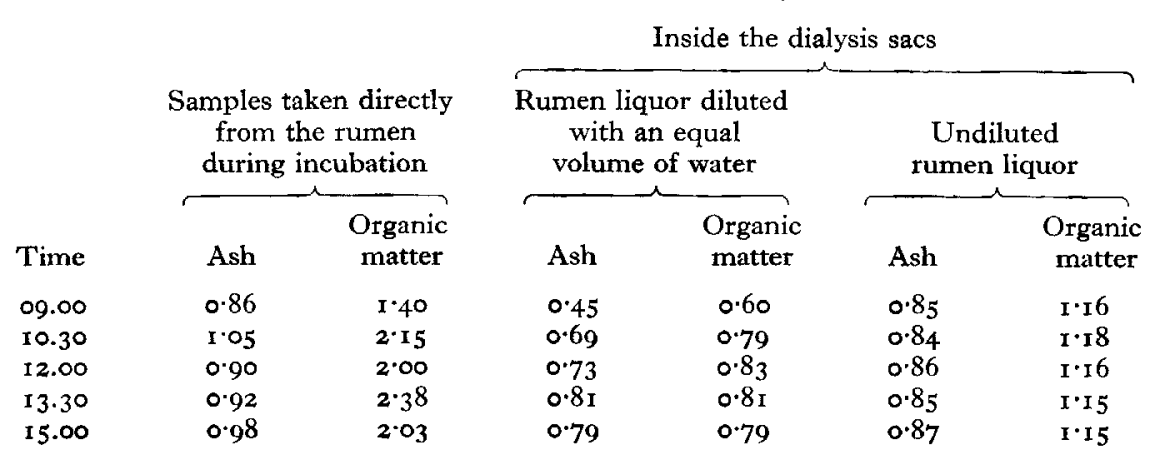

Reproducibility of the sampling technique. In this experiment, a comparison was made of the compositions of samples taken at different times from the reaction vessels. Vessel I contained $60 \mathrm{ml}$ strained, but not centrifuged rumen liquor and $60 \mathrm{ml}$ water, and vessel 2 contained $\mathrm{I} 20 \mathrm{ml}$ of the same rumen liquor undiluted. Vessel 3 contained no dialysis membrane. Samples ( $\mathrm{IO} \mathrm{ml}$ ) were withdrawn from the first and the second vessels, and from the rumen through vessel 3 , and their dry-matter and ash contents 
were determined. The organic matter concentration was found by difference. The results are shown in Table 2. The ash and organic matter concentrations in the undiluted rumen liquor did not change appreciably during incubation for $6 \mathrm{~h}$. From 09.00 to $10.30 \mathrm{~h}$ there was a marked increase in the concentration of organic matter in the diluted rumen liquor. "The concentration of ash in the diluted sample gradually increased to reach a steady value close to that of the undiluted sample in about $4 \mathrm{~h}$. It was found during other experiments that, if the rumen liquor was diluted with artificial saliva (ash content $\mathrm{I} \cdot 05 \%$ ) instead of water, the ash concentration remained approximately the same throughout the incubation. The concentrations of both these components in samples withdrawn directly from the rumen were more variable and, in general, were higher than the corresponding concentrations in the samples withdrawn from the vessel containing the undiluted rumen liquor. It was concluded from the regularity of the results obtained from the two reaction vessels, compared with the variability of samples obtained directly from the rumen, that the adopted stirring and sampling procedure was satisfactory.

Volume of the reaction mixture during incubation. Since water might diffuse between the vessels and the rumen contents, the volume of the reaction mixtures was measured by determining the volume of the mixture left in the incubation vessels at the end of the experiment and adding it to the sum of the volumes of the samples that had been taken. The recovery was normally between 97 and $100 \%$. In some experiments polyethylene glycol was incorporated in the reaction mixtures as a reference substance, and its concentration determined by the method of Hydén (I96r). This led to an increase in the volume owing to an infusion of water from outside caused by the polymer and this procedure was abandoned.

Size and type of inoculum. The most suitable size and type of inoculum depended on the type of incubation. If it was desired to study microbial growth, the best results were obtained when the inoculum constituted $20-30 \%$ of the total volume incubated. Experiments in which the hydrogenation of unsaturated fatty acids was studied normally necessitated a larger proportion of rumen liquor $(50-70 \%)$.

Some of the results illustrating the effect of the size of inoculum and the effect of substrate concentration are shown in Figs. 3 and 4. In one experiment (Fig. 3), each of the three vessels contained $20 \mathrm{ml}$ of a solution of urea $(5 \circ \mathrm{mg})$ and glucose $(5 \circ \mathrm{mg})$. Inocula of strained rumen liquor $(20,40$ and $60 \mathrm{ml})$ were added to vessels $\mathrm{I}, 2$ and 3 respectively, and the volume was made up with artificial saliva to $100 \mathrm{ml}$ in each vessel. Samples were withdrawn at hourly intervals and centrifuged at $100 \mathrm{~g}$ for $10 \mathrm{~min}$ and the turbidity of the supernatant fluid was determined. The $20 \%$ inoculum gave the greatest growth.

There was little growth of bacteria (as measured turbidimetrically after centrifuging; Fig. 3) when large ( 40 and $60 \mathrm{ml}$ ) inocula of strained uncentrifuged rumen liquor were used. Possibly under these conditions the substrate (glucose) was limiting because of its large uptake by protozoa which were also present.

The experiment illustrated in Fig. 4 was of a different type; the inoculum was the supernatant fluid obtained from rumen liquor which had been previously centrifuged for $10 \mathrm{~min}$ at $100 \mathrm{~g}$ to remove protozoa and other large particles. Each vessel contained 
$40 \mathrm{ml}$ artificial saliva and $20 \mathrm{ml}$ urea-glucose solution $(50 \mathrm{mg}$ of urea in each vessel; $50 \mathrm{mg}$ glucose in vessel $\mathrm{I}$, $100 \mathrm{mg}$ in vessel 2 and $200 \mathrm{mg}$ in vessel 3 ). The extent of microbial growth increased with the concentration of glucose, but the addition of large amounts of glucose $(200 \mathrm{mg})$ led to decrease in this rate after $3 \mathrm{~h}$ due, presumably, to inhibition by products of microbial metabolism.

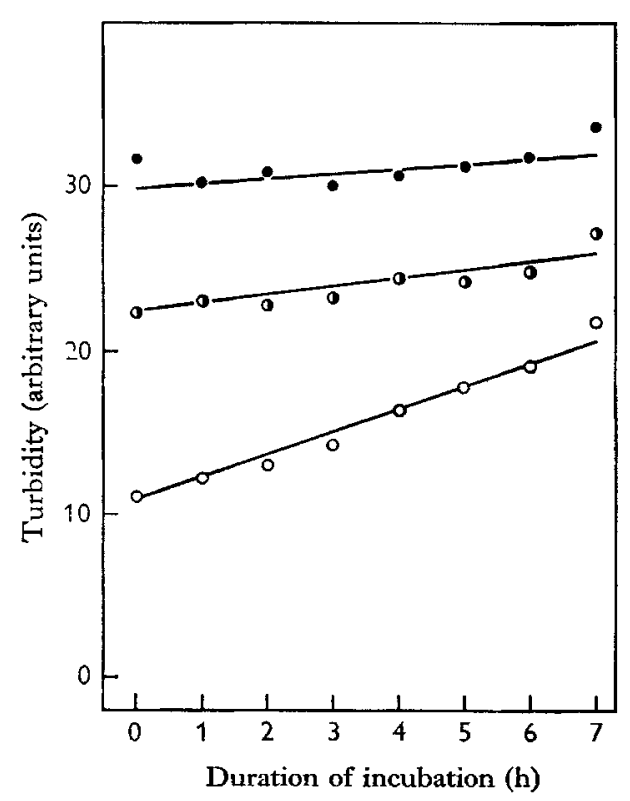

Fig. 3

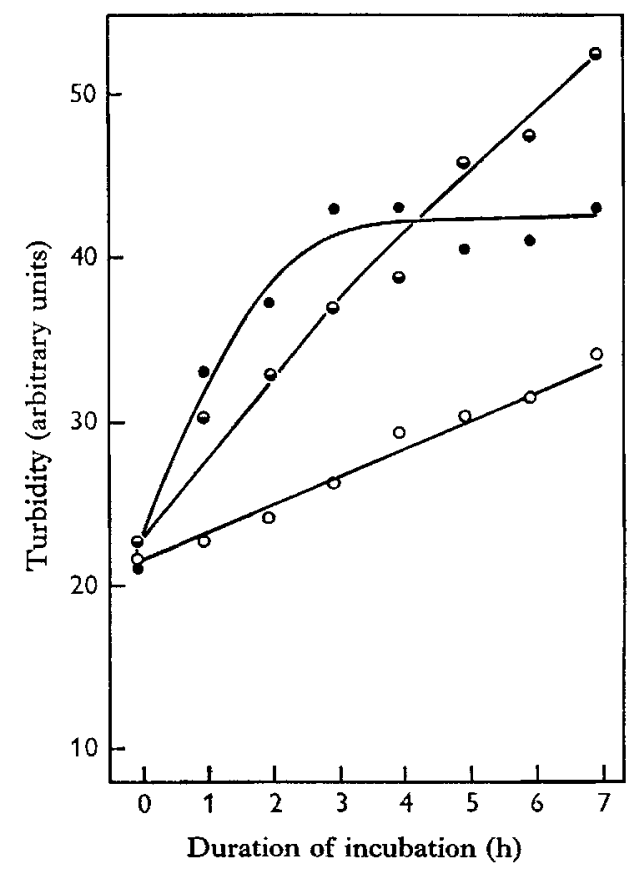

Fig. 4

Fig. 3. Effect of size of inoculum, as a percentage of the contents of the dialysis sacs, suspended in the rumen, on microbial growth, as shown by the turbidity of diluted samples. For details see p. 872. $O, 20 \%$ inoculum; $140 \%$ inoculum; $0,50 \%$ inoculum.

Fig. 4. Effect of the concentration of glucose on microbial growth using protozoa-free inoculum. $0,50 \mathrm{mg} / 100 \mathrm{ml} ; \ominus, 100 \mathrm{mg} / 100 \mathrm{ml} ; 0,200 \mathrm{mg} / 100 \mathrm{ml}$. The experimental details are given in the text.

\section{Microbial growth and protein synthesis}

Protein is not distributed uniformly in rumen liquor. A proportion of it is found in the protozoa which are readily sedimented during centrifuging at low speed. The residue contains large particles of dietary origin that are rich in plant protein. The supernatant fluid contains bacterial protein, and also much soluble protein from dietary or other sources, some of which is ultimately digested by the micro-organisms. Thus the measurement of protein concentration as an index of microbial growth is not the best procedure unless special precautions are taken. Very often, an increase in microbial protein is masked by a simultaneous decrease in the dietary protein. Net protein synthesis could be readily demonstrated when the animal was given a poor diet and the inoculum was small (Fig. 5, open circles). These results were obtained by determining the concentration of protein in samples (the turbidities of these samples are given in Fig. 3, open circles). When the animal received a rich diet $(6 \mathrm{~kg}$ cubes and 
$6 \mathrm{~kg}$ hay) and a fairly large inoculum of rumen liquor was used (50\%) there was usually at first a small but consistent increase in the protein nitrogen and this was followed by a steady decrease (Fig. 5, the two upper curves, where the concentration of protein nitrogen was determined by two different methods).

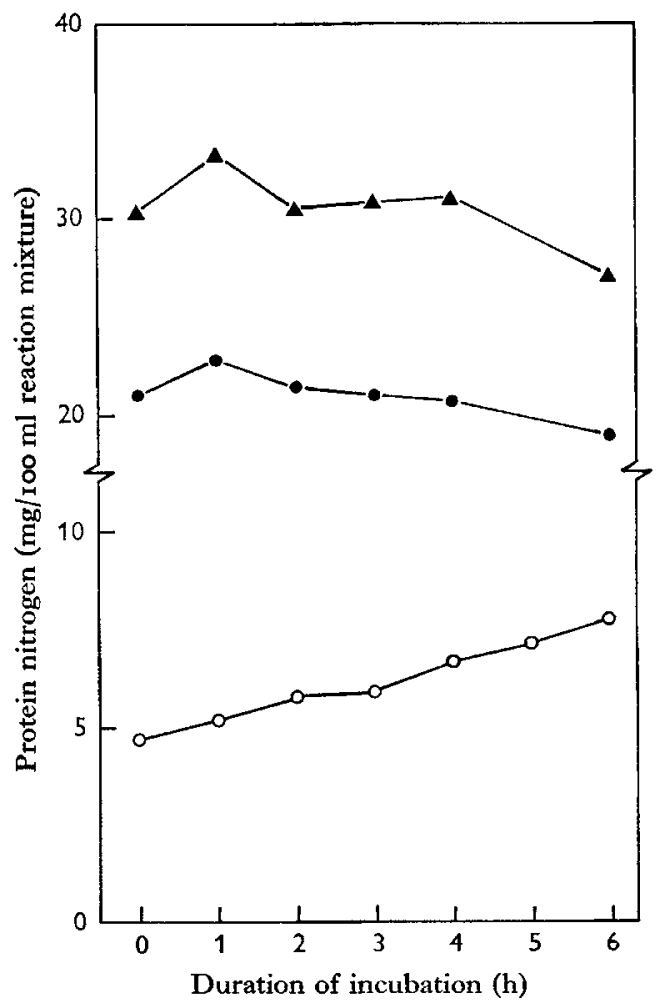

Fig. 5. Protein concentration as a measure of microbial growth in dialysis sacs suspended in the rumen. The two upper curves show the results of an experiment in which the cow was on a protein-rich diet and in which a heavy inoculum of rumen liquor was used. The protein was determined as nitrogen precipitable by trichloroacetic acid ( $\mathbf{\Delta})$, and by the method of Lowry et al. (I95I) (O). The lowest curve, $O$, represents the results obtained with a cow given a poorer diet and shows the increase in the concentration of protein determined by the method of Lowry et al. (I95I) on the samples whose turbidity is given in Fig. 3 (20\% inoculum).

\section{Hydrogenation of unsaturated fatty acids}

When a moderate amount of an emulsion of fatty acids is mixed with strained rumen liquor, the fatty acids are rapidly taken up by the particles (bacteria, protozoa and fragments of food). When such a mixture was centrifuged at $20000 \mathrm{~g}$ for $30 \mathrm{~min}$ and the fatty acids were extracted separately from the residue and from the supernatant fluid, it was found that a large proportion of the added fatty acids became associated with the residue (Ulyatt, Czerkawski \& Blaxter, 1966). Thus, incubation of long-chain fatty acids in the semi-permeable sacs inside the rumen should not lead to their loss provided they are mixed with the rumen liquor, and provided they are not broken during the incubation. 
Table 3. Recovery of fatty acids added to rumen liquor from a cow and after mixture of fatty acids had been incubated in the rumen for periods ranging from $\circ$ to $23 h$

Lipid (mg/roo $\mathrm{ml}$ reaction mixture)

\section{Control}

Low amounts of fatty acids addcd

Higher amounts of fatty acids added

$\begin{array}{ccc}\begin{array}{c}\text { Nominal } \\ \text { amount } \\ \text { added }\end{array} & \begin{array}{l}\text { Amount } \\ \text { isolated* }\end{array} & \text { Increment } \\ - & 49.9 \pm 2.7 & - \\ 65 & 106.3 \pm 4.4 & 56.4 \dagger \\ 150 & 183.6 \pm 4.2 & 133.7 \dagger\end{array}$

* Mean with standard error for six samples taken after time intervals ranging from $\circ$ to $23 \mathrm{~h}$.

+ Corresponds to recovery of over $85 \%$.

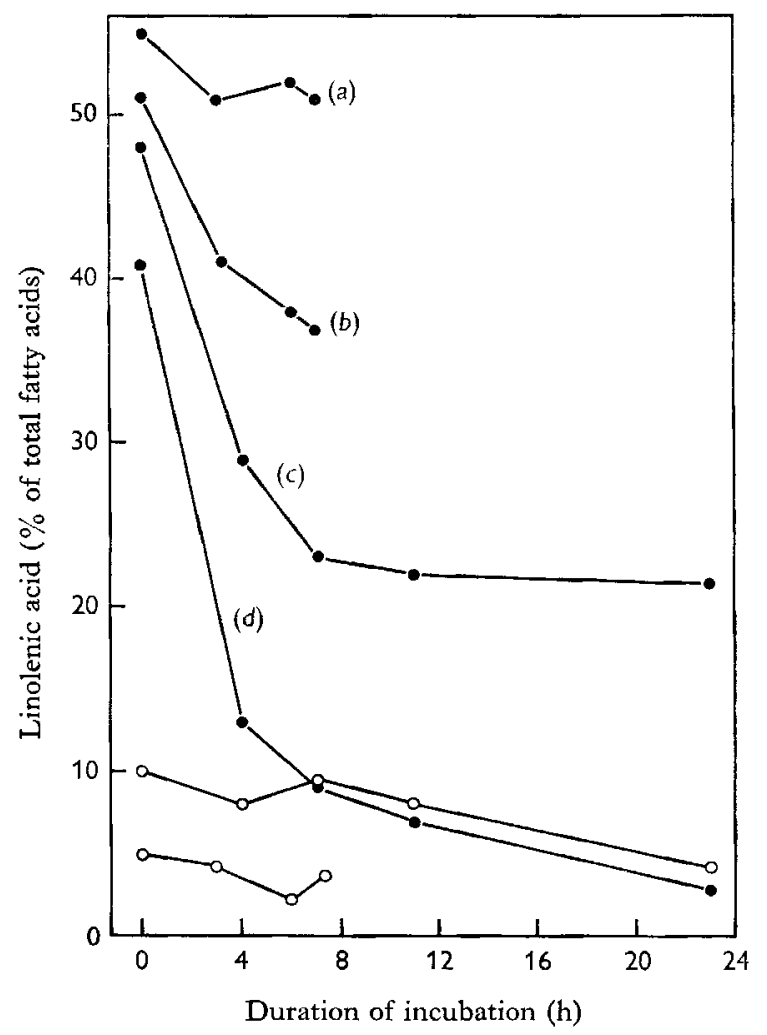

Fig. 6. Disappearance of linolenic acid during incubation of linseed oil fatty acids with rumen liquor. $O$, control experiments with no fatty acids added; $\bullet$, experiments in which the following amounts of linseed oil fatty acids were added per r $20 \mathrm{ml}$ reaction mixturc: $(a)$ $300 \mathrm{mg},(b) 200 \mathrm{mg},(c) 150 \mathrm{mg},(d) 60 \mathrm{mg}$.

The isolation of fatty acids involves many steps and is subject to large errors. The recovery of the added fatty acids was ascertained by determining the amounts of crude lipid in samples from the incubation vessels taken over periods of up to $23 \mathrm{~h}$ and comparing them with the amounts of crude lipid in the control vessel where no fatty acids were added. Some results are shown in Table 3 . The recovery of fatty acids, 
after subtraction of the control value, was equivalent to about $88 \%$ of the amount added and there was no tendency for the recovery to increase or decrease as the time of incubation progressed.

The amounts of fatty acids used were important because at high concentration they were toxic to micro-organisms. The emulsion of linseed oil fatty acids was prepared by half-neutralizing the oil with $\mathrm{N}-\mathrm{NaOH}$ and homogenizing the mixture in a Waring Blendor. Suitable amounts (containing between 60 and $300 \mathrm{mg}$ fatty acids in $20 \mathrm{ml}$ of

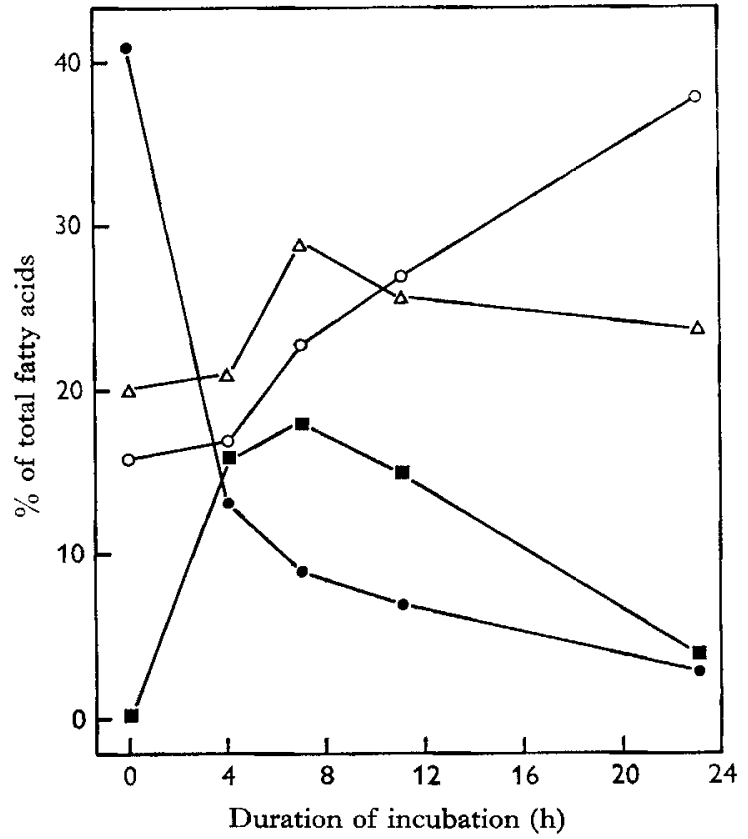

Fig. 7. Changes in the major constituents of $\mathrm{C}_{18}$ fatty acids during incubation of $60 \mathrm{mg}$ linseed oil fatty acids with $120 \mathrm{ml}$ rumen liquor. $O$, linolenic acid; $\triangle$, monoenoic $C_{18}$ acids (mainly trans); $\mathrm{O}$, stearic acid; $\square$, compound identified tentatively as the non-conjugated cis-trans dienoic $\mathrm{C}_{18}$ acid.

emulsion) were added to the incubation vessels containing $20 \mathrm{ml}$ of artificial saliva and $80 \mathrm{ml}$ of strained rumen liquor. Samples were withdrawn at regular intervals for periods of up to $23 \mathrm{~h}$ and analysed. Some of the results, giving the concentration of linolenic acid (the major component of linseed oil fatty acids) in the total fatty acids, are summarized in Fig. 6 . With the smaller amounts of fatty acids $(60 \mathrm{mg} / 100 \mathrm{ml})$, the concentration of linolenic acid decreased rapidly.

Many of the samples obtained during incubations were examined under a lowpower $(3 \circ x)$ microscope to observe the behaviour of the protozoal population, which in the samples studied was varied and plentiful. This was of particular interest when the linseed oil fatty acids were added to the incubation mixtures. When the amounts added were large (150 $\mathrm{mg} / 100 \mathrm{ml}$ reaction mixture or more), the normally active protozoa became sluggish and a large proportion seemed to be dead after $6-7 \mathrm{~h}$ of incubation. When the amounts of fatty acid were small $(30-60 \mathrm{mg} / 100 \mathrm{ml}$ reaction 
mixture), the protozoa were very active and remained so during the incubation. It appeared during direct comparison with the control samples (no fatty acid added), that the activity of the protozoa was increased when small amounts of fatty acids were added. This might have some bearing on the reported observation (Gutierrez, Williams, Davis \& Warwick, 1962) that protozoal fermentation could be stimulated by certain fatty acids.

The concentrations of $\mathrm{C}_{18}$ acids other than linolenic were also measured and some results of a typical experiment are given in Fig. 7 . There was a steady increase in the concentration of stearic acid, the ultimate product of hydrogenation of linolenic acid. The concentration of the $\mathrm{C}_{\mathbf{1 8}}$ monoenoic acids increased initially and then decreased. Trans-isomers constituted a large proportion of these acids. The non-conjugated cistrans isomer of linoleic acid was identified tentatively by its retention volume during gas-liquid chromatography. Its retention volume relative to stearic acid $\left(I \cdot 3^{6}\right)$ on polyethylene glycol adipate columns was only slightly greater than the relative retention volume of linoleic acid (I.29). On the non-polar Apiezon columns this isomer coincided with the $\mathrm{C}_{18}$ trans-monoenoic acids. The approximate concentrations of the non-conjugated cis-trans isomer were calculated by difference. The results, which at best were semi-quantitative, are shown in Fig. 7. They suggest that this component is an intermediary in the hydrogenation of linolenic acid in the rumen and they are in broad agreement with the scheme given by Wilde \& Dawson (1966).

\section{DISCUSSION}

A technique resembling the one used here was described by Fina, Teresa \& Bartley (1958) who used suitably mounted porous porcelain tubes to incubate samples of rumen liquor inside the rumen. There was no provision for sampling or stirring, and there were other limitations, such as irregularity of pore size in the tubes, difficulty of cleaning them between experiments, and the use of relatively small volumes. A modified form of apparatus, utilizing micropore membranes, was described more recently by Fina, Keith, Bartley, Hartman \& Jacobson (I962). They also found that Visking dialysis membranes are quite suitable, although it is surprising that they could be used safely for periods of up to 5 days. The vessels used by these authors were small $(20 \mathrm{ml})$ and the ratio of semi-permeable area to volume was $0.6 \mathrm{~cm}^{2} / \mathrm{ml}$ in their stainless steel apparatus and 0.3 in their glass Vivar jars. The ratio of semipermeable area to volume in the apparatus described here was $\mathrm{I} \cdot 3 \mathrm{~cm}^{2} / \mathrm{ml}$.

The apparatus now described is not difficult to construct; it is capable of giving reproducible results, and can be adapted for investigations of different aspects of fcrmentation in the rumen. The apparatus provides results in conditions similar to those obtained in vivo, and yet does not suffer from the difficulties associated with other types of studies of fermentation inside the rumen, namely, poor sampling and flow of the reaction medium. The micro-organisms, the food particles, compounds with high molecular weight, and under certain conditions compounds of small molecular weight, such as the long-chain fatty acids, are kept in a closed system. This system differs to some extent from that in the unenclosed rumen contents but such 
differences could be advantageous. For example, hydrogenation of unsaturated fatty acids by mixed rumen micro-organisms in vitro leads to the formation of conjugated acids (Kepler, Hirons, McNeill \& Toves, 1965) - compounds which are found only in small amounts in the normal rumen. The non-conjugated cis-trans isomer of $\mathrm{C}_{18}$ dienoic acid is not normally detected in the rumen, presumably because of the continuous flow of digesta and because of the rapidity of its further hydrogenation. The present method is sufficiently natural to avoid the formation of appreciable amounts of conjugated acids, but at the same time it is artificial enough to lead to a temporary accumulation of the non-conjugated cis-trans isomer of linoleic acid.

I am grateful to Dr J. H. Moore for helpful discussions and to Miss G. Breckenridge and $\mathrm{Mrs} \mathrm{C}$. Faulds for extensive analytical assistance. I am grateful also to Mr D. Paterson for supervision of the various incubation and sampling procedures, and to Mr J. Henderson for help in constructing the apparatus.

I acknowledge a gift of Netlon tubing kindly provided by Spicers Ltd, Loughton, Essex.

\section{REFERENCES}

Alexander, R. H. \& McGowan, M. (I966). Br. Grassld Soc. 21, I40.

Balch, C. C. \& Cowie, A. T. (1962). Cornell Vet. 52, 206.

Conway, E. J. (1962). In Microdiffusion Analysis and Volumetric Error, p. 234. London: Crosby, Lockwood and Son Ltd.

Czerkawski, J. W. (1966). Biochem. F. 99, 39P.

Dawson, R. M. C., Ward, P. F. V. \& Scott, T. W. (1964). Biochem. F. 9o, 9.

Duncombe, W. G. (1963). Biochem. F. 88, 7 .

Fina, L. R., Keith, C. L., Bartley, E. E., Hartman, P. A. \& Jacobson, N. L. (I962). F. Anim. Sci. 21, 930.

Fina, L. R., Teresa, G. W. \& Bartley, E. E. (1958). 7. Anim. Sci. 17, 667.

Folch, J., Lees, M. \& Stanley, G. H. S. (1957). F. biol. Chem. 226, 497.

Gutierrez, J., Williams, P. P., Davis, R. E. \& Warwick, E. J. (1962). Appl. Microbiol. 1o, 548.

Hale, E. B., Duncan, C. W. \& Huffman, C. F. (1947). F. Nutr. 34, 747.

Hydén, S. (196I). LantbrHögsk. Annlr 27, 5 I.

Jacobs, S. (1960). Analyst 85, 257.

Kates, M. (1964). F. Lipid Res. 5, I32.

Kepler, C. R., Hirons, K. P., McNeill, J. J. \& Toves, S. B. (ı 965). Fedn Proc. Fedn Am. Socs exp. Biol. 24, 290.

Lowry, O. H., Rosebrough, N. J., Farr, A. L. \& Randall, R. J. (1951). F. biol. Chem. 193, 265.

McDougall, E. I. (I948). Biochem. F. 43, 99.

Tennies, G. \& Feng, F. (1965). Analyt. Biochem. II, 41 I.

Ulyatt, M. J., Czerkawski, J. W. \& Blaxter, K. L. (1966). Proc. Nutr. Soc. 25, xviii.

Warner, A. C. I. (1956). \%. gen. Microbiol. 14, 733-

Wilde, P. F. \& Dawson, R. M. C. (I966). Biachem. Y. 98, 469.

\section{EXPLANATION OF PLATE}

\section{Plate I}

Apparatus for incubation of rumen liquor in semi-permeable sacs inside the bovine rumen. $(A)$ The block with three cylindrical vessels, with one stopper and stirrer assembled as it would be during incubation. $(B)$ An inner supporting cylinder and dialysis tube complete with stirrer, polythene ring and collar (syringe also shown). (C) The stopper and stirrer assembly, the latter partly pulled out to show the stirring arrangement. (D) Plastic tube which fits on to the rubber collar of the stirrer tube and is then used to rotate the stirrer. $(E)$ The inner supporting cylinder, collar, ring and rubber bung shown separated. $(F)$ Rubber cover which fits into the flap of the cannula. The scale is approximately $I: 3$. 
British Fournal of Nutrition, Vol. 21, No. 4

Plate I

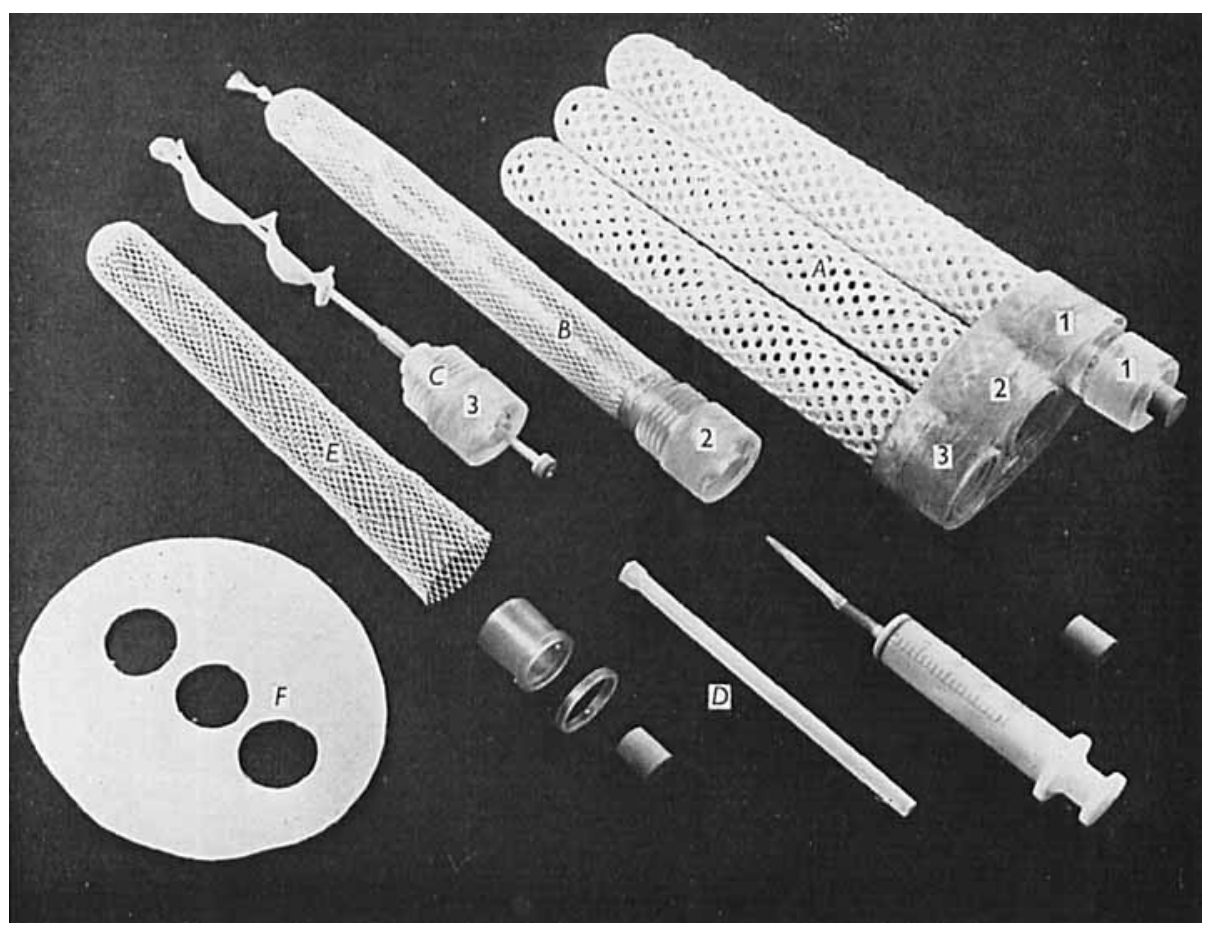

